OPEN ACCESS

Edited by:

Loredana Albonici,

University of Rome Tor Vergata, Italy

Reviewed by:

Jamshid Hadjati,

Tehran University of Medical Sciences,

Kevin Van der Jeught, Indiana University School of Medicine

United States

${ }^{*}$ Correspondence:

Diego O. Croci

dcrocirusso@gmail.com

Specialty section:

This article was submitted to

Cancer Immunity and

Immunotherapy,

a section of the journal

Frontiers in Immunology

Received: 30 January 2021

Accepted: 21 April 2021

Published: 07 May 2021

Citation:

Bannoud N, Dalotto-Moreno T, Kindgard L, García PA, Blidner AG,

Mariño KV, Rabinovich GA and

Croci DO (2021) Hypoxia Supports

Differentiation of Terminally

Exhausted CD8 T Cells.

Front. Immunol. 12:660944.

doi: 10.3389/fimmu.2021.660944

\section{Hypoxia Supports Differentiation of Terminally Exhausted CD8 T Cells}

\author{
Nadia Bannoud ${ }^{1,2}$, Tomás Dalotto-Moreno ${ }^{3}$, Lucía Kindgard ${ }^{1}$, Pablo A. García ${ }^{1}$, \\ Ada G. Blidner ${ }^{3}$, Karina V. Mariño ${ }^{4}$, Gabriel A. Rabinovich ${ }^{3,5}$ and Diego O. Croci ${ }^{1,6 *}$ \\ 1 Laboratorio de Inmunopatología, Instituto de Histología y Embriología de Mendoza (IHEM), Consejo Nacional de \\ Investigaciones Científicas y Técnicas (CONICET), Mendoza, Argentina, 2 Facultad de Ciencias Médicas, Universidad \\ Nacional de Cuyo, Mendoza, Argentina, ${ }^{3}$ Laboratorio de Inmunopatología, Instituto de Biología y Medicina Experimental \\ (IBYME), Consejo Nacional de Investigaciones Científicas y Técnicas (CONICET), Buenos Aires, Argentina, ${ }^{4}$ Laboratorio de \\ Glicómica Funcional y Molecular, Instituto de Biología y Medicina Experimental (IBYME), Consejo Nacional de Investigaciones \\ Científicas y Técnicas (CONICET), Buenos Aires, Argentina, ${ }^{5}$ Facultad de Ciencias Exactas y Naturales, Universidad de \\ Buenos Aires, Buenos Aires, Argentina, ${ }^{6}$ Facultad de Ciencias Exactas y Naturales, Universidad Nacional de Cuyo, \\ Mendoza, Argentina
}

Hypoxia, angiogenesis, and immunosuppression have been proposed to be interrelated events that fuel tumor progression and impair the clinical effectiveness of anti-tumor therapies. Here we present new mechanistic data highlighting the role of hypoxia in finetuning CD8 T cell exhaustion in vitro, in an attempt to reconcile seemingly opposite evidence regarding the impact of hypoxia on functional features of exhausted CD8 T cells. Focusing on the recently characterized terminally-differentiated and progenitor exhausted CD8 T cells, we found that both hypoxia and its regulated mediator, vascular endothelial growth factor (VEGF)-A, promote the differentiation of PD $-1^{+} \mathrm{TIM}-3^{+} \mathrm{CXCR} 5^{+}$terminally exhausted-like CD8 T cells at the expense of PD- $1^{+}$TIM- $3^{-}$progenitor-like subsets without affecting tumor necrosis factor (TNF)- $\alpha$ and interferon (IFN)- $\gamma$ production or granzyme $B$ (GZMB) expression by these subpopulations. Interestingly, hypoxia accentuated the proangiogenic secretory profile in exhausted CD8 T cells. VEGF-A was the main factor differentially secreted by exhausted CD8 T cells under hypoxic conditions. In this sense, we found that VEGF-A contributes to generation of terminally exhausted CD8 T cells during in vitro differentiation. Altogether, our findings highlight the reciprocal regulation between hypoxia, angiogenesis, and immunosuppression, providing a rational basis to optimize synergistic combinations of antiangiogenic and immunotherapeutic strategies, with the overarching goal of improving the efficacy of these treatments.

Keywords: Hypoxia, CD8 T cell exhaustion, immunosuppression, VEGF-A, anti cancer agents

\section{INTRODUCTION}

In the past years, it has become increasingly clear that tumor cells alone are not sufficient to generate cancer. The tumor microenvironment (TME) (i.e.: endothelial vascular and lymphatic cells, immune cells and stromal fibroblasts, among others) are key players in tumor progression $(1,2)$ and play a central role in acquired resistance to targeted therapies $(3,4)$. In this regard, the TME has been proposed to be an attractive target for the generation of anticancer therapies including immunotherapy, antiangiogenic and 
targeted therapies $(4,5)$. Antiangiogenic therapies target the ability of cancer cells to generate an abnormal vasculature that engenders a hostile microenvironment. Strikingly, major hallmarks of this adverse scenario are hypoxia and acidic $\mathrm{pH}$, which fuel immunosuppression and promote impairment of effector T-cell function $(6,7)$. In this scenario, tumor hypoxia emerges as a major driving force that influences not only malignant cells but also the TME, impairing effector immune responses and promoting angiogenesis, by affecting cell migration and endothelial cell adhesion or directly influencing immune cell differentiation and function $(8,9)$. In this sense, immunomodulatory molecules such as vascular endothelial growth factor (VEGF-A), hepatocyte growth factor (HGF), angiopoietins, adenosine, transforming growth factor- $\beta$ (TGF- $\beta$ ), and galectins (9-11) are key soluble mediators that link these pro-tumoral functions (12).

Despite significant progress in understanding the molecular components of hypoxia-regulated programs in the TME (13), the cellular mechanisms and mediators coupling tumor hypoxia and CD8 $\mathrm{T}$ cell exhaustion remain elusive. Although the programs that govern $\mathrm{T}$ cell exhaustion are still under debate, there is a consensus that it comprises phenotypically and functionally heterogeneous exhausted CD8 (exhCD8) T cells. In this perspective article, we discuss the role of hypoxia in finetuning CD8 T-cell exhaustion, in an attempt to reconcile previous studies and emerging evidence describing functional features of newly characterized terminal and progenitor features of newly characterized terminal and progenitor exhCD8 T cells.

\section{HYPOXIA IN THE PROMOTION OF IMMUNE TOLERANCE}

Tumor hypoxia impairs immune responses by influencing mechanisms that bribe immune cells to become immunosuppressive (14). These molecular pathways include the hypoxia inducible factor- 1 alpha (HIF-1 $\alpha$ )-dependent induction and recruitment of Foxp $3^{+}$regulatory $\mathrm{T}$ cells (Tregs) through mechanisms involving TGF- $\beta$-driven STAT-3 signaling $(15,16)$, the release of CCL28 chemokine by tumor cells (17) and CCL22 by tumor-associated macrophages (TAMs) (18). Moreover, T cell receptor (TCR) cross-linking in HIF-1 $\alpha$-deficient T cells skews the balance towards a pro-inflammatory cytokine profile (19), suggesting that HIF-1 $\alpha$ may function as a negative regulator of $\mathrm{T}$-cell differentiation and cytokine production.

Hypoxia has also been associated with dysregulated activity of tumor-associated myeloid cells (20-22). Differentiation, recruitment, and polarization of TAMs may be regulated by tumor cells via VEGF-A, HIF- $1 \alpha$ and CCL2-dependent mechanisms $(23,24)$. Tumor cell expression of VEGF-A contributes to recruitment of Tregs to the TME (25), promotes CD8 $\mathrm{T}$ cell exhaustion (26), and impairs dendritic cell (DC) maturation (27). Furthermore, under hypoxic conditions HIF$1 \alpha$, but not HIF- $2 \alpha$ activation contributes to up-regulation of PD-L1 in myeloid-derived suppressor cells (MDSCs), TAMs, and DCs, endowing these cells with tolerogenic activity (28-30). These data suggest that simultaneous blockade of HIF- $1 \alpha$ and immune checkpoints such as programmed death-1 (PD-1) and cytotoxic T-lymphocyte antigen-4 (CTLA-4) could represent a novel approach for combinatorial cancer immunotherapy.

Despite the well-established proangiogenic and antiinflammatory roles of hypoxia through the stabilization of HIF$\alpha$ proteins, more recent studies revealed that these transcription factors contribute to inflammation by promoting Th17 cell differentiation $(31,32)$. Additionally, prolyl hydroxylase proteins (PHD), together with $v h l$ genes, induce $\mathrm{O}_{2}$-tagged-dependent HIF-1 $\alpha$ degradation; this effect restrains the function of CD4 and CD8 T cells and increases Treg cell expansion in lung tissues, thereby promoting a permissive niche for lung metastasis $(33,34)$. These data highlight the need of further exploration of the interplay between hypoxia and inflammation in the TME. In this complex scenario, the impact of hypoxia in CD8 $\mathrm{T}$ cell immunoregulation is not fully understood.

\section{CD8 T CELL EXHAUSTION}

Exhausted $\mathrm{T}$ cells were initially described as hyporesponsive or hypofunctional effector $\mathrm{T}$ cells characterized by sustained expression of multiple inhibitory receptors, progressive loss of effector functions (cytotoxicity and cytokine production), reduced proliferative capacity, altered expression and function of key transcription factors and dysregulation of epigenetic programs. Even though these phenotypic features have been widely used as hallmarks of T-cell exhaustion programs, enabling the distinction of naive $(\mathrm{Tn})$, effector ( $\mathrm{T}$ eff) and memory T cells $(\mathrm{Tm})(35,36)$, recent transcriptional and epigenetic studies have demonstrated that exhaustion is not merely a transient impairment of the functionality of $\mathrm{T}$ cells. Instead, T-cell exhaustion involves distinct states of T-cell differentiation with a continuum of phenotypic and functional intermediate states $(37,38)$. Thus, a deeper understanding of the factors that control exhaustion programs is central for shaping the course of chronic infections and cancer.

During an acute immune response, immune receptors are transiently expressed by Tef cells to limit immunopathology and autoimmunity $(39,40)$. However, in chronic infections and cancer, sustained expression of immune checkpoint molecules gives rise to the expansion of exhausted T cells. Among these coinhibitory molecules, CTLA-4 (CD152), PD-1 (CD279), T cell immunoglobulin domain and mucin domain-containing protein 3 (TIM-3/HAVCR2/CD366), lymphocyte activation gene-3 (LAG-3/CD223), T cell immunoreceptor with Ig and ITIM domains (TIGIT), B and T lymphocyte attenuator (BTLA/ CD272), 2B4 (CD244) and CD160 (41-43), play key roles in $\mathrm{T}$-cell exhaustion and represent important targets for the design of new generation anticancer immunotherapies (42).

Although different signals may promote CD8 T-cell exhaustion, persistent antigen stimulation appears to be the major driving force leading to a T-cell exhausted phenotype $(37,44)$. Impairment of CD8 T-cell functionality is favored when CD4 T-cell function is affected by diminished IL-21 production $(45,46)$. Moreover, increased levels of pro-inflammatory cytokines, such as type I interferons (IFNs) and IL-6, or immunosuppressive cytokines 
including IL-10 and TGF- $\beta 1(45,47)$ contribute to shape an exhausted phenotype. In addition, microenvironmental factors, such as hypoxia and nutrient deprivation (e.g., glucose, amino acids, glutamine), can limit T-cell activity and consequently impair the immune response by modulating metabolic pathways (42, 48, 49). Thus, T-cell exhaustion represents an evolutionary adaptation to conditions of chronic antigen stimulation and inflammation (38), favoring tissue repair following an inflammatory injury.

Recently, high-dimensional studies identified approximately nine phenotypic subtypes of exhausted T cells (50), but to date two major subsets of exhCD8 T cells have been described, namely progenitor or stem-like subset, and terminallyexhausted populations (Figure 1A) $(36,38)$. The identification and characterization of these exhCD8 $\mathrm{T}$ cell subpopulations represents a paradigm shift in the conception of cytotoxic $\mathrm{T}$ cells during the course of antitumor responses. Notably, the balance between progenitor and terminally exhCD8 $\mathrm{T}$ cells determines the cytotoxic potential and longevity required for mounting an effective immune response (41).

The so called exhCD8 $\mathrm{T}$ cells progenitor population can be defined as PD- $1^{\text {int }}(36)$ CXCR5 $^{+}(51)$ or Slamf6 ${ }^{+} / \operatorname{Ly} 108(38,52)$ lacking expression of TIM-3 (51), while terminally exhCD8 T cells are identified as PD- $1^{\text {hi }}(36,37)$ or ${\text { TIM }-3^{+}}^{+}(37,51)$. Although several transcription factors have been proposed as key determinants of exhaustion programs, recent studies highlighted a dynamic interplay between $\mathrm{T}$ Cell Factor-1 (TCF-1) and thymocyte selection-associated high mobility group box protein (TOX), in the control of different exhausted populations $(51,53-56)$. TCF-1-expressing progenitor T cells are also characterized by enhanced proliferative capacity, polyfunctional cytokine production, and long-term persistence in the absence of antigen. Two progenitor interchangeable states have been described with functional and anatomical differences, but similar epigenetic programming that can be catalogued in the lymphoid tissue resident Texh Prog1 and the blood accessible Texh Prog2, which eventually give rise to terminally exh T cells inside the tumor tissue or inflammatory site (53). The terminally exhCD8 $\mathrm{T}$ cells are characterized by coexpression of $\mathrm{B}$ lymphocyte-induced maturation protein-1 (Blimp-1) (56) and effector genes (e.g. GZMB), which sustain their cytotoxic activity, and exhibit reduced long-term survival and polyfunctional cytokine production (41). The main implications of the two subsets of CD8 T cells in TME rely on their potential to respond to $\mathrm{PD}-1$ immune checkpoint blockade (ICB); the progenitor

A

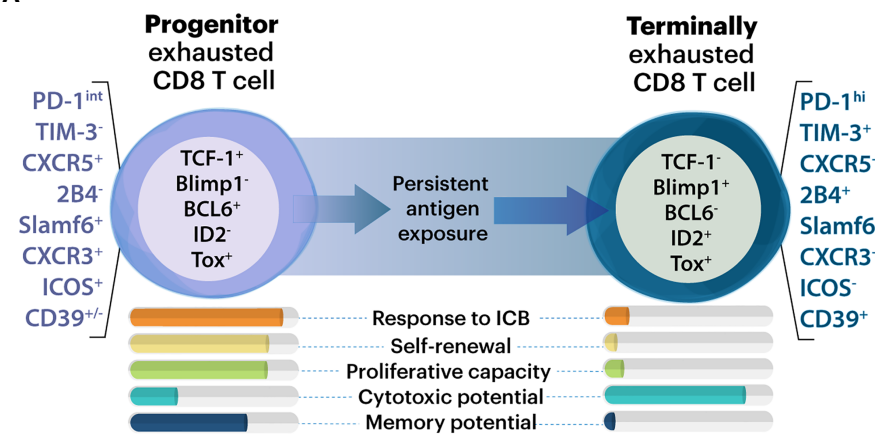

B

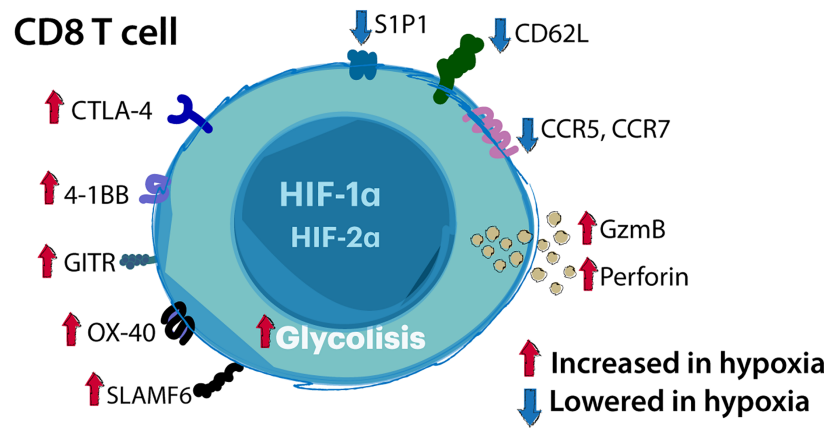

FIGURE 1 | Association between CD8 T cell exhaustion and hypoxia. (A) Schematic representation of progenitor and terminally exhausted T cell subsets. Although T cell exhaustion comprises a wide range of exhausted states, two major subsets of exhCD8 T cells have been studied in detail: the progenitor and the terminally exhausted $T$ cell population. Whereas progenitor exhausted T cells exhibit proliferative potential, and stemness properties and can be rescued by immune checkpoint blockade (ICB) therapies, terminally exhausted T cells have higher cytotoxic potential but represent a terminal differentiation state and cannot be rescued by ICB. Proposed key molecules which discriminate these subpopulations are listed. (B) Modulation of CD8 T cell functions by hypoxia. Through HIF-1 $\alpha$ and HIF2 $\alpha-$ dependent mechanisms, hypoxic stimuli favor glycolytic anaerobic metabolism promoting $T$ cell receptor (TCR) signaling. These include enhanced perforin and granzyme-B (GzmB) release as well as expression of immune checkpoint molecules (including both activators and inhibitors). Hypoxia inhibits expression of chemokine and cytokine receptors and adhesion molecules. 
population expands giving rise to terminally-differentiated exhausted subsets $(38,51)$, a primary cytotoxic CD8 T cell population in the TME. Therefore, a balance of both progenitor and terminally-exhausted populations may be required for effective control of tumors and chronic infections $(36,38)$. With the major goal of improving therapeutic interventions, new studies are required to explore the relevance of these phenotypical changes in pathophysiological settings and their crosstalk with environmental factors in inflammatory and TME.

\section{HYPOXIA MODULATES CD8 T CELL DIFFERENTIATION}

CD8 $\mathrm{T}$ cell reinvigoration and its relevance in immunotherapy have been extensively discussed $(41,57)$. However, the role of hypoxia in shaping the phenotype of these cells is a matter of debate. In tumors, adipocyte tissue, and secondary lymphoid organs, CD8 T cells are preferentially localized in hypoxic zones $(58,59)$. In pioneering studies, hypoxia was reported as a critical factor that potentiates CD8 T cells lytic properties but interrupts their development $(60,61)$ (Figure 1B). In this sense, VHLmediated HIF- $1 \alpha$ and HIF- $2 \alpha$ stabilization blunts the differentiation of CD8 $\mathrm{T}$ cells in vitro but increases GZMB expression, promoting the capacity of these cells to control tumor growth and persistent viral infections (34). Additionally, GZMB and the activation-associated costimulatory receptors 41BB, GITR, and OX40 were found to be increased in CD8 T cells exposed to hypoxia (62). In this sense, HIF-1 $\alpha$ but not HIF-2 $\alpha$ drives CD8 T cell migration and effector function (63). However, the expression of key immune checkpoint receptors such as LAG-3 and CTLA-4 was also increased in these CD8 T cells under hypoxia in a VHL/HIF-1 $\alpha$-dependent mechanism (34). In addition, hypoxia fuels $\mathrm{T}$ cell exhaustion through a miRNA-24dependent MYC dysregulation that affects mitochondrial function and metabolism (64), suggesting a complex regulatory program driven by hypoxia in CD8 $\mathrm{T}$ cells.

Interestingly, the relevance of hypoxic regions in the tumor tissue varies from acute hypoxia surrounding blood vessels that slowly consolidates in chronic hypoxia according to oxygen supply. The interplay between distinct hypoxic stages may determine local $\mathrm{T}$ cell cytotoxicity and global success of a wide variety of therapies (65). On the other hand, residence of TCF1 ${ }^{+}$ CD8 progenitor T cells appear to depend on $\mathrm{MHCII}^{\mathrm{hi}} \mathrm{DC}$ niches that ensure their survival and further conversion to a differentiated late exhausted and highly cytotoxic progeny. Notably, these tertiary lymphoid structures correlate with lymphatic and blood vessel infiltration into the tumor (66). In conclusion, these data suggest a spatial correlation between immunosuppression, hypoxia and terminally-differentiated exhausted T cells.

Under hypoxia, the primary biological mediator of HIF activation is VEGF-A (67). In addition to its functions as a regulator of the angiogenic process (68), this growth factor promotes a dysfunctional phenotype in CD8 T cells by increasing the expression of co-inhibitory molecules including PD-1, CTLA-4, and TIM-3 (26, 63). Moreover, VEGF-A upregulation in microsatellite stable colorectal cancers promotes resistance to antiPD-1 immunotherapy by antagonizing the effector function of CD8 $\mathrm{T}$ cells and favoring expansion of exhCD8 T cells via induction of a TOX-mediated transcriptional program (69). Under hypoxic conditions, CD8 T cells maintain or even increase their cytotoxic capacity but slow down their development, secrete less IFN- $\gamma$ and IL-2, and enhance the expression of immune inhibitory checkpoints $(58,69)$. However, evidence linking hypoxia to exhCD8 T cell differentiation is still scarce. To fill this gap and reconcile the apparently controversial data, we conducted in vitro experiments exploring how hypoxia influences generation and functionality of different subsets of exhCD8 T cells.

\section{HYPOXIA AND VEGF-A FAVOR DIFFERENTIATION TO TERMINALLY EXHAUSTED CD8 T CELLS}

In order to address the role of hypoxia in exhCD8 $\mathrm{T}$ cell differentiation, we first performed in vitro experiments (Figure 2A) exposing differentiated exhCD8 $T$ cells to hypoxic or normoxic conditions, and explored the frequency and functionality of the different exhCD8 $\mathrm{T}$ cells subsets (Figures 2B-D). According to previous reports, in vitro differentiation of $\mathrm{CD}^{+} \mathrm{T}$ cells resulted in an exhausted phenotype characterized by expression of PD- 1 and TIM- 3 co-inhibitory receptors (63, 69). Among them, two subpopulations can be clearly distinguishable as $\mathrm{PD}^{+}{ }^{+} \mathrm{TIM}^{-}$and $\mathrm{PD}^{+}{ }^{+} \mathrm{TIM}^{+}$(Figure 2A). While the former displayed a phenotype characterized by lower cytotoxic potential, demonstrated by GzmB expression and $\mathrm{CD} 107 \mathrm{a}$ mobilization, the latter $\left(\mathrm{PD}^{+} \mathrm{TIM}^{+}\right)$subpopulation exhibited an increased cytotoxic potential (Figure 2B), with higher expression of TNF- $\alpha$ and IFN- $\gamma$, compared with the PD ${ }^{+}{ }^{+}$TIM $3^{-}$cells (Figure 2B). These features are consistent with the two well-characterized exhCD8 $\mathrm{T}$ populations recognized so far, the progenitor and the terminally exhausted subsets (37). In this sense, and as previously reported, hypoxic conditions enhanced the cytotoxic profile of $\mathrm{CD}^{+} \mathrm{T}$ cells, assessed by GzmB expression and CD107a mobilization to the cell surface (Figure 2C). Notably, when we further analyzed CD8 $\mathrm{T}$ subpopulations, we found that hypoxia increased the percentage of terminally exhausted-like cells at the expense of the progenitor-like subset (Figure 2D). We confirmed that $\mathrm{PD}^{+}{ }^{+} \mathrm{TIM}^{-}$cells expressed $\mathrm{CXCR}^{+}$, a typical marker of the progenitor exhausted phenotype (51), while $\mathrm{PD}^{+}{ }^{+} \mathrm{TIM}^{+}$cells displayed a terminally exhausted-like phenotype (Figure 2D). Nonetheless, no differences in cytokine production were observed in these populations under hypoxic conditions (Figure 2E), suggesting that hypoxia favors the generation of a terminally exhausted phenotype in CD8 T cells with no evident changes in their cytokine secretion profile.

To study whether hypoxia could affect secretion of proangiogenic factors, we performed an angiogenic cytokine array to assess cytokines expressed by naïve, activated, and exhCD8 T cells, under normoxic or hypoxic conditions. Interestingly, 
A
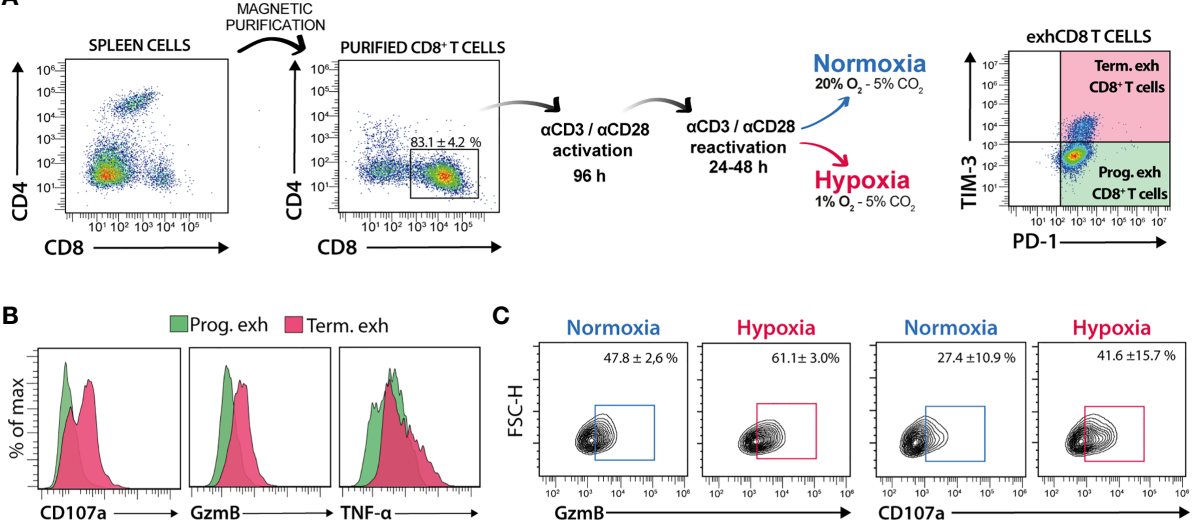

D
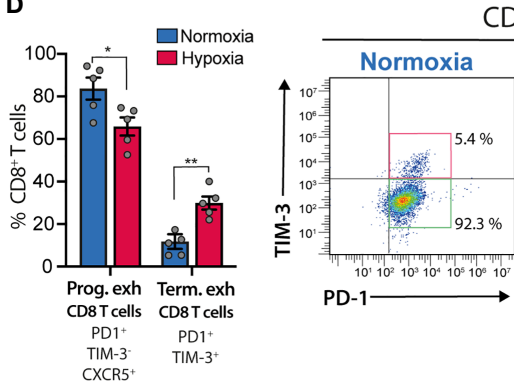

CD8 ${ }^{+} \mathrm{T}$ cells
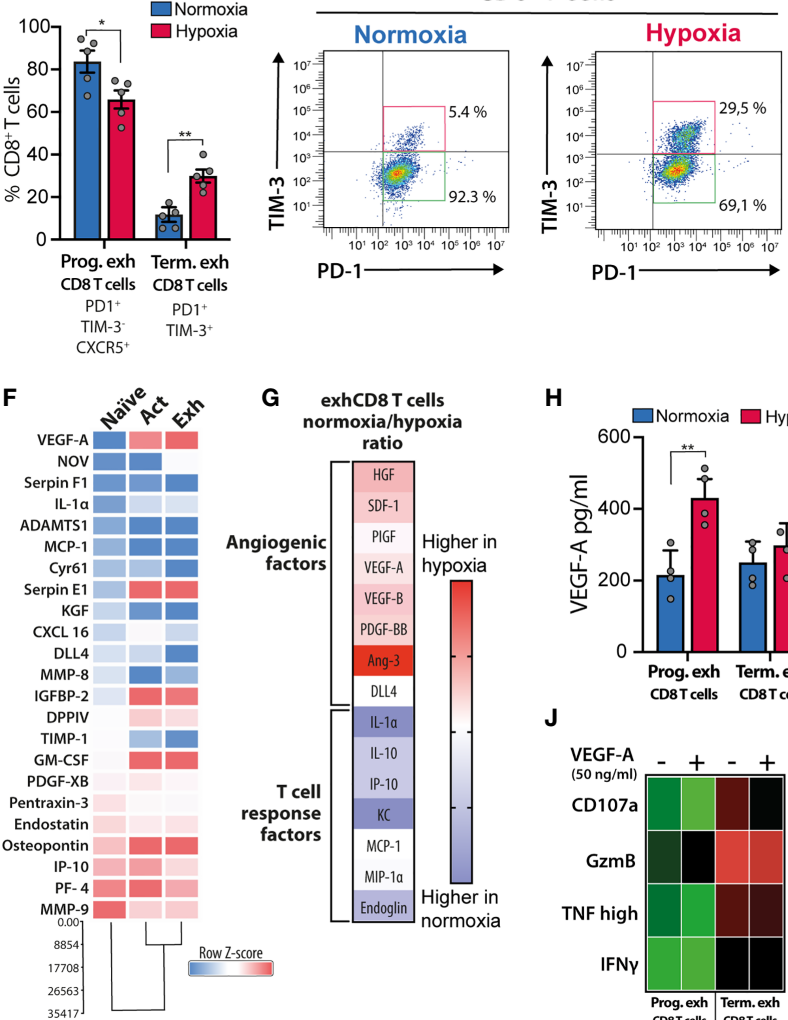

E $\square$ Normoxia $\square$ Hypoxia

H
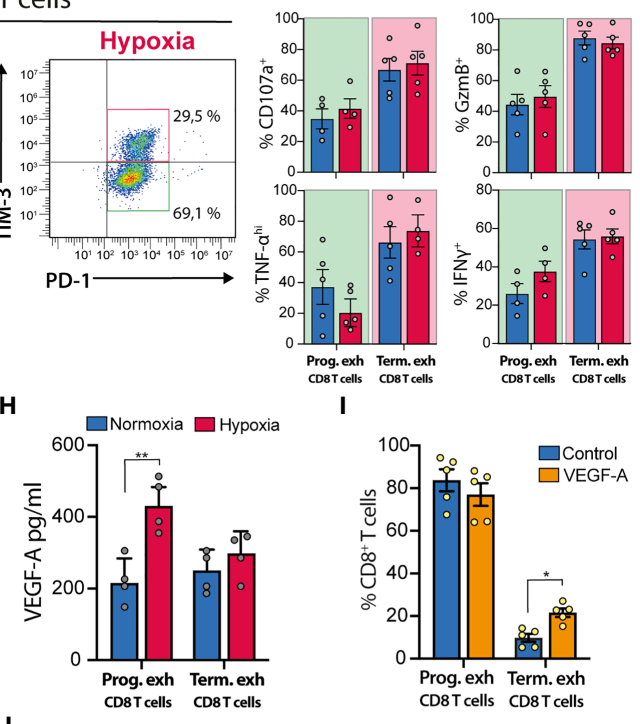

I

$\mathbf{J}$
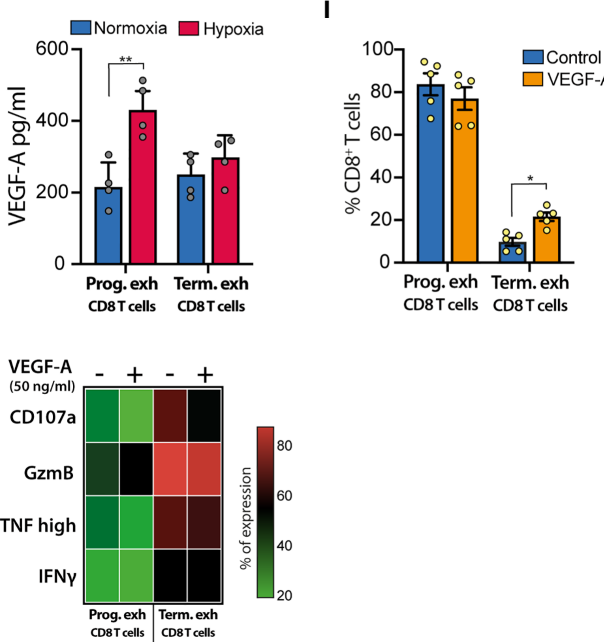

FIGURE 2 | Hypoxia and VEGF-A promote differentiation of terminally exhCD8 T cells. (A) Schematic representation of workflow and gating strategy for in vitro differentiation of exhCD8 T cells. (B) Representative histograms showing intracellular staining of CD107a, Granzyme-B (GzmB), and TNF- $\alpha$ in progenitor (green) or terminally (pink) exhCD8 T cells. (C) Representative contour plots showing GzmB and CD107a expression in CD8 $8^{+}$PD- $1^{+} \mathrm{T}$ cells after $24 \mathrm{~h}$ exposure to hypoxia (1\% $\mathrm{O}_{2}$ ) or normoxia $\left(20 \% \mathrm{O}_{2}\right)$. (D) Differentiation of PD- $1^{+} \mathrm{TIM}-3^{-} \mathrm{CXCR} 5^{+}$progenitor exhCD8 T cells and PD- $1^{+} \mathrm{TIM}-3^{+}$terminally exhCD8 $\mathrm{T}$ cells under normoxic (blue bars) or hypoxic (red bars) conditions. Left, percentage of each subpopulation. Right, representative density plots showing the subpopulations. Data are the mean \pm SEM of five independent experiments. (E) Determination of cytokine expression by intracellular flow cytometry in different exhCD8 T cell subpopulations under normoxic or hypoxic conditions. Data are the mean \pm SEM of 4 independent experiments. (F) Heat map representing normalized row Z-score of semiquantitative cytokine array analysis of angiogenic factors secreted by $\mathrm{CD} 8^{+} \mathrm{T}$ cells during the differentiation process. Data shows densitometric determinations and cluster analysis of pooled supernatants from five independent experiments. (G) Representation of the ratio of cytokines secreted by exhCD8 T cells under normoxic or hypoxic conditions. Heat maps represent the ratio of normalized densitometric data for each cytokine in normoxia versus hypoxia. (H) VEGF secretion by PD-1 $1^{+} \mathrm{TIM}-$ $3^{-} \mathrm{CXCR}^{+}$progenitor exhCD8 T cells and PD- $1^{+} \mathrm{TIM}-3^{+}$terminally exhCD8 T cells under normoxic (blue bars) or hypoxic (red bars) conditions. Data are the mean \pm SEM of four independent experiments. (I) Differentiation of PD- $1^{+} \mathrm{TIM}-3^{-} \mathrm{CXCR} 5^{+}$progenitor exhCD8 $\mathrm{T}$ cells and PD $-1^{+} \mathrm{TIM}-3^{+}$terminally exhCD8 T cells in the presence (orange bars) or in the absence (blue bars) of VEGF-A (50 ng/ml). Data are the mean \pm SEM of five independent experiments. (J) Heat map representation of intracellular cytokines determined by flow cytometry in different exhCD8 T cells subpopulations in the presence or the absence of VEGF-A (50 ng/ml). Each row represents the mean \pm SEM of the percentage of cells expressing each cytokine in four independent experiments. ${ }^{*} p<0.05,{ }^{* *} p<0.01$. 
activation of $\mathrm{CD}^{+} \mathrm{T}$ cells imprinted these cells with a predominant proangiogenic phenotype, characterized by greater secretion of soluble proangiogenic factors (Figure 2F). Moreover, hypoxia-driven differentiation of terminally exhausted $\mathrm{T}$ cells resulted in enhanced expression of proangiogenic mediators when compared with exhCD8 $\mathrm{T}$ cells exposed to normoxic conditions (Figure 2G). Under hypoxic conditions, differentiated exhCD8 T cells displayed a broad proangiogenic program characterized by higher levels of proangiogenic molecules such as VEGF-A, platelet-derived growth factor (PDGF), placental growth factor (PIGF), and angiopoietin-3 (Ang3). On the other hand, under normoxic conditions, exhCD8 $\mathrm{T}$ cells showed a secretome associated with regulation of $\mathrm{T}$ cell responses, as shown by IL-10 and the cell surface receptor endoglin, a component of the TGF- $\beta$ signaling receptor family (Figure 2G). Interestingly, hypoxia selectively increased VEGF-A secretion in the progenitor exhCD8 T cell subset (Figure $\mathbf{2 H}$ ).

Finally, given the role of VEGF-A in promoting CD8 T cell exhaustion (26) and its regulated expression in exhCD8 $\mathrm{T}$ cell subsets differentiation in vitro (Figures $\mathbf{2 F}-\mathbf{H}$ ), we explored its effects in the frequency of progenitor and terminally exhCD8 $\mathrm{T}$ cell subsets. Remarkably, VEGF-A (50 ng/ml) favored the differentiation of $\mathrm{CD}^{+} \mathrm{T}$ cells toward a terminally exhaustedlike phenotype (Figure 2I), although at a lesser extent than hypoxia. Of note, VEGF-A did not alter the percentage of cells expressing CD107a, GzmB, TNF- $\alpha$, or IFN- $\gamma$ among the different exhCD8 $\mathrm{T}$ cell populations (Figure 2J). Thus, increased frequency of terminally-exhausted-like cells arising following exposure to hypoxic conditions, could be attributed, at least in part, to the effects of VEGF-A.

\section{METHODS}

Splenic $\mathrm{CD}^{+} \mathrm{T}$ cells were obtained from C57BL/6 mice bred at the animal facility of Instituto de Histología y Embriología de Mendoza (IHEM) according to NIH Guidelines for the Care and Use of Animals. All procedures were approved by the Institutional Animal Care and Use Committee of the School of Medical Science, Universidad Nacional de Cuyo (Protocol approval $\mathrm{N}^{\circ}$ 111/2017). $\mathrm{CD}^{+} \mathrm{T}$ cells were isolated using the Dynabeads Untouched Mouse CD8 cells kit (Invitrogen) and subsequently seeded ( $5 \times 10^{5}$ cells $/ \mathrm{mL}$ ) in RPMI supplemented with $10 \%$ fetal bovine serum (FBS) (Gibco) and $5.5 \times 10^{-5} \mathrm{M} 2$ mercaptoethanol, in 48-well culture plates. In vitro stimulation was performed with immobilized anti-CD3 antibody $(2.5 \mu \mathrm{g} / \mathrm{mL}$; Clone BD Biosciences) and anti-CD28 antibody $(2 \mu \mathrm{g} / \mathrm{mL}$; Clone BD Biosciences). After $96 \mathrm{~h}$, cells were re-stimulated with antiCD3 $(1.5 \mu \mathrm{g} / \mathrm{mL})$ and anti-CD28 $(1 \mu \mathrm{g} / \mathrm{mL})$ antibodies in $10 \%$ FBS RPMI. $\mathrm{CD}^{+} \mathrm{T}$ cells were incubated under hypoxia in a modular incubator chamber (Billups-Rothenberg, San Diego, CA, USA), flushed at 2 psi for 10 min with a mixture of $1 \%$ $\mathrm{O}_{2}, 5 \% \mathrm{CO}_{2}$, and $94 \% \mathrm{~N}_{2}$. The chamber was sealed and placed in a $37^{\circ} \mathrm{C}$ incubator for $48 \mathrm{~h}$. Control $\mathrm{CD}^{+} \mathrm{T}$ cells were placed in the same incubator at $20 \% \mathrm{O}_{2}$. Cell cultures in both conditions were then incubated with VEGF-A ( $50 \mathrm{ng} / \mathrm{ml}$, R\&D systems) for $24 \mathrm{~h}$ at $37^{\circ} \mathrm{C}$. The Zombie Green Fixable Viability Kit (Biolegend, San Diego, CA, USA) was used to exclude dead cells. $\mathrm{CD}^{+} \mathrm{T}$ cells were phenotyped by cell surface staining with anti-CD4 (clone GK1.5), anti-CD8 (clone 53-6.7), anti-TIM-3 (clone RMT3-23) anti-PD1 (clone RMP1-14) and anti-CXCR5 (clone L138D7) antibodies (all from Biolegend) in 1\% BSA in PBS for $20 \mathrm{~min}$ at $4^{\circ} \mathrm{C}$. For intracellular staining, cells were permeabilized with BD Perm/Wash buffer (BD Biosciences) and further stained with anti-Gzm-B (clone 6B11; e-biosciences) and anti-TNF- $\alpha$ (clone MP6-XT22), anti-IFN- $\gamma$ (clone XMG1.2) and antiCD107a (clone 1D4B), all from BD Pharmigen. To assess cytokine production, $\mathrm{CD}^{+} \mathrm{T}$ cells were incubated with PMA (50 ng/mL, Sigma), ionomycin $(1 \mu \mathrm{g} / \mathrm{mL}$, Sigma) and monensin (Golgi STOP, BD Biosciences) at $37^{\circ} \mathrm{C}$. Cells were harvested after $4 \mathrm{~h}$ and intracellular cytokines were evaluated by flow cytometry. Experiments were performed in a BD Accuri C6 Plus flow cytometer (BD Biosciences) and data was analyzed with FlowJo V10.7.1 software.

Cytokine arrays were performed with the Proteome Profiler Mouse XL Cytokine Array (R\&D Systems) following manufacturer's instructions using conditioned media from $\mathrm{CD}^{+} \mathrm{T}$ cells obtained after the differentiation process and exposed to hypoxic or normoxic conditions. Murine VEGF-A secretion was determined by ELISA (R\&D systems) in conditioned media from previously sorted progenitor or terminally exhCD8 T cells.

Statistical analysis and data representation was performed using GraphPad Prism 8.2.1 Software (GraphPad, CA, USA). Student's $t$ test was used for unpaired data. Two-way ANOVA and Dunnett's or Tukey post-tests were used for multiple comparisons. Cluster differentiation analysis from normalized row Z-score values was performed with Infostat software. $P$ values of 0.05 or less were considered significant. Exact $P$ values are reported in all figures.

\section{DISCUSSION}

In the past years, combination therapies have changed the landscape of cancer treatment (70). Interestingly, combinations of antiangiogenic therapies and ICB are currently being evaluated in several tumor types $(9,70,71)$. Hypoxia, the primary driving force responsible of triggering vascularization programs, has come into the spotlight because of its concomitant immunosuppressive activity in the $\operatorname{TME}(72,73)$. Hypoxia promotes $\mathrm{T}$ cell activation and cytotoxic activities and favors the development of exhaustion programs (4). Although there are no studies focused on the role of hypoxia or VEGF-A on different exhCD8 T cell subpopulations, it is known that expression of TIM-3, a signature of terminally-exhausted T cells, is highly upregulated under hypoxic conditions $(26,63,74)$.

Here, we showed that hypoxia promotes the differentiation of PD $-1^{+}$TIM $-3^{+}$terminally exhCD8 T cells at the expense of the PD- ${ }^{+}$TIM- $3^{-} \mathrm{CXCR}^{+}$progenitor-like population. Although these cells exhibit a highly cytotoxic-like phenotype $(38,74)$, they are resistant to ICB therapies. In fact, it has been recently 
proposed that anti-PD1 antibodies targets the progenitor exhausted TILs, but not the terminally-exhausted T cells (38, 75). Thus, favoring expansion of the progenitor exhCD8 $\mathrm{T}$ cells might improve responses to ICB.

In this sense, Voron and colleagues demonstrated that VEGF-A increases the percentages of TIM- $3^{+-}$expressing $\mathrm{CD} 8^{+} \mathrm{T}$ cells and highlighted the role of VEGF-A in resistance to anti-PD-1 treatment in a murine model of colorectal cancer (26). Then, Palazon and colleagues confirmed and expanded these findings suggesting a direct role of HIF- $1 \alpha$ as an essential regulator of T cell effector responses in the TME through mechanisms involving VEGF-A regulation, angiogenesis, and $\mathrm{T}$ cell migration (63). In this sense, we found an up-regulation of pro-angiogenic factors upon $\mathrm{T}$ cell activation. Furthermore, in exhCD8 T cells hypoxia imprints a pro-angiogenic program characterized by up-regulation of Ang-3, PDGF, hepatocyte growth factor (HGF), and VEGF-A. In this regard, our study demonstrates that VEGF-A promotes CD8 T cell exhaustion by increasing the frequency of terminally-exhausted T cells. Moreover, our results, albeit limited to in vitro experiments, suggest a cross-talk between vascular and immune cell programs which target exhausted $\mathrm{T}$ cells and simultaneously foster immune escape and neovascularization. These results support the rationale of improving combinatorial therapies using HIF inhibitors or antiangiogenic therapies plus ICB in highly hypoxic tumors (70).

Although further studies are needed to understand how hypoxia links immune tolerance and angiogenesis and sustains resistance to anti-tumor therapies, studies in clear cell renal cell carcinoma (ccRCC) could give a preliminary insight into this possibility. This tumor is characterized by a high $\mathrm{CD}^{+} \mathrm{T}$ cell infiltration and loss of the tumor suppressor von Hippel-Lindau (VHL), which promotes HIF stabilization leading to activation of several oxygenindependent hypoxic transcriptional programs. In ccRCC tumors, CD8 $\mathrm{T}$ cell infiltration rate is typically associated with poor prognosis (76), imposing hurdles to most immunotherapeutic modalities (77). In this sense, and in line with our hypothesis, Siska and colleagues reported that phenotypical and functional differences of CD8 T cells from ccRCC involve constitutive activation of HIF-1 $\alpha$, which promotes an altered metabolism (78). These results shed light on the complex relationships between HIF activation and CD8 T cell functionality in the TME.

In conclusion, our findings suggest that hypoxic programs may represent an attractive target to attenuate $\mathrm{T}$ cell exhaustion and immunosuppression in the TME. However, further studies in vivo are required to examine the role of hypoxia, its cellular mediators and signaling pathways in supporting tumor-immune escape and $\mathrm{T}$ cell exhaustion in antigen-specific and pathologic settings. Further investigation should be aimed at exploring the intimate link between hypoxia, immunosuppression, and

\section{REFERENCES}

1. Coussens LM, Zitvogel L, Palucka AK. Neutralizing Tumor-Promoting Chronic Inflammation: A Magic Bullet? Science (2013) 339:286-91. doi: $10.1126 /$ science. 1232227

2. Quail DF, Joyce JA. Microenvironmental Regulation of Tumor Progression and Metastasis. Nat Med (2013) 19:1423-37. doi: 10.1038/nm.3394 angiogenesis with the ultimate goal of designing more effective combinatorial modalities for treating cancer patients.

\section{DATA AVAILABILITY STATEMENT}

The raw data supporting the conclusions of this article will be made available by the authors, without undue reservation.

\section{ETHICS STATEMENT}

All procedures were approved by the Institutional Animal Care and Use Committee of the School of Medical Sciences, Universidad Nacional de Cuyo. Approval No 111/2017.

\section{AUTHOR CONTRIBUTIONS}

NB acquired, analyzed, and interpreted data, supervised the study, and wrote the manuscript. TD-M interpreted data and revised the manuscript. LK acquired, analyzed, and interpreted data, PG analyzed and interpreted data, and revised the manuscript. $\mathrm{AB}$ interpreted data and revised the manuscript. KM interpreted data and revised the manuscript. GR conceived and supervised the study and wrote the manuscript. DC conceived, designed, and supervised the study, interpreted data, and wrote the manuscript. All authors contributed to the article and approved the submitted version.

\section{FUNDING}

This work was supported by grants from the Argentinean Agency for Promotion of Science and Technology PICT 20160205 to DC and PICT 2017-0494 to GR, and Secretaría de Investigación, Relaciones Internacionales y Posgrado, SIIPUNCuyo J069 to NB and DC. This work was also supported by the NIH grants U54 CA 0221208 to DC and GR.

\section{ACKNOWLEDGMENTS}

We thank Julieta Scelta for technical assistance. We specially thank the contribution of Fundación Sales and Fundación Bunge \& Born. We thank the support of Ferioli, Ostry, and Caraballo families.

3. Junttila MR, de Sauvage FJ. Influence of Tumour Micro-Environment Heterogeneity on Therapeutic Response. Nature (2013) 501:346-54. doi: 10.1038 /nature12626

4. Petitprez F, Meylan M, de Reynies A, Sautes-Fridman C, Fridman WH. The Tumor Microenvironment in the Response to Immune Checkpoint Blockade Therapies. Front Immunol (2020) 11:784. doi: 10.3389/fimmu.2020.00784

5. Pardoll DM. The Blockade of Immune Checkpoints in Cancer Immunotherapy. Nat Rev Cancer (2012) 12:252-64. doi: 10.1038/nrc3239 
6. Munn LL, Jain RK. Vascular Regulation of Antitumor Immunity. Science (2019) 365:544-5. doi: 10.1126/science.aaw7875

7. Mendez-Huergo SP, Blidner AG, Rabinovich GA. Galectins: Emerging Regulatory Checkpoints Linking Tumor Immunity and Angiogenesis. Curr Opin Immunol (2017) 45:8-15. doi: 10.1016/j.coi.2016.12.003

8. Chouaib S, Messai Y, Couve S, Escudier B, Hasmim M, Noman MZ. Hypoxia Promotes Tumor Growth in Linking Angiogenesis to Immune Escape. Front Immunol (2012) 3:21. doi: 10.3389/fimmu.2012.00021

9. Khan KA, Kerbel RS. Improving Immunotherapy Outcomes With AntiAngiogenic Treatments and Vice Versa. Nat Rev Clin Oncol (2018) 15:31024. doi: $10.1038 /$ nrclinonc. 2018.9

10. Croci DO, Salatino M, Rubinstein N, Cerliani JP, Cavallin LE, Leung HJ, et al. Disrupting Galectin-1 Interactions With N-glycans Suppresses HypoxiaDriven Angiogenesis and Tumorigenesis in Kaposi's Sarcoma. J Exp Med (2012) 209:1985-2000. doi: 10.1084/jem.20111665

11. Martin JD, Seano G, Jain RK. Normalizing Function of Tumor Vessels: Progress, Opportunities, and Challenges. Annu Rev Physiol (2019) 81:50534. doi: 10.1146/annurev-physiol-020518-114700

12. Croci DO, Cerliani JP, Pinto NA, Morosi LG, Rabinovich GA. Regulatory Role of Glycans in the Control of Hypoxia-Driven Angiogenesis and Sensitivity to Anti-Angiogenic Treatment. Glycobiology (2014) 24:1283-90. doi: 10.1093/ glycob/cwu083

13. LaGory EL, Giaccia AJ. The Ever-Expanding Role of HIF in Tumour and Stromal Biology. Nat Cell Biol (2016) 18:356-65. doi: 10.1038/ncb3330

14. Hanahan D, Coussens LM. Accessories to the Crime: Functions of Cells Recruited to the Tumor Microenvironment. Cancer Cell (2012) 21:309-22. doi: $10.1016 /$ j.ccr.2012.02.022

15. Deng B, Zhu JM, Wang Y, Liu TT, Ding YB, Xiao WM, et al. Intratumor Hypoxia Promotes Immune Tolerance by Inducing Regulatory T Cells Via TGF-beta1 in Gastric Cancer. PloS One (2013) 8:e63777. doi: 10.1371/ journal.pone.0063777

16. Wei J, Wu A, Kong LY, Wang Y, Fuller G, Fokt I, et al. Hypoxia Potentiates Glioma-Mediated Immunosuppression. PloS One (2011) 6:e16195. doi: 10.1371/journal.pone.0016195

17. Facciabene A, Peng X, Hagemann IS, Balint K, Barchetti A, Wang LP, et al. Tumour Hypoxia Promotes Tolerance and Angiogenesis Via CCL28 and T (reg) Cells. Nature (2011) 475:226-30. doi: 10.1038/nature10169

18. Curiel TJ, Coukos G, Zou L, Alvarez X, Cheng P, Mottram P, et al. Specific Recruitment of Regulatory $\mathrm{T}$ Cells in Ovarian Carcinoma Fosters Immune Privilege and Predicts Reduced Survival. Nat Med (2004) 10:942-9. doi: $10.1038 / \mathrm{nm} 1093$

19. Lukashev D, Klebanov B, Kojima H, Grinberg A, Ohta A, Berenfeld L, et al. Cutting Edge: Hypoxia-Inducible Factor 1alpha and its Activation-Inducible Short Isoform I.1 Negatively Regulate Functions of CD4+ and CD8+ T Lymphocytes. J Immunol (2006) 177:4962-5. doi: 10.4049/jimmunol. 177.8.4962

20. Gabrilovich DI, Ostrand-Rosenberg S, Bronte V. Coordinated Regulation of Myeloid Cells by Tumours. Nat Rev Immunol (2012) 12:253-68. doi: 10.1038/ nri3175

21. Yang M, Ma C, Liu S, Shao Q, Gao W, Song B, et al. HIF-Dependent Induction of Adenosine Receptor A2b Skews Human Dendritic Cells to a Th2stimulating Phenotype Under Hypoxia. Immunol Cell Biol (2010) 88:16571. doi: $10.1038 /$ icb.2009.77

22. Corzo CA, Condamine T, Lu L, Cotter MJ, Youn JI, Cheng P, et al. Hif-1alpha Regulates Function and Differentiation of Myeloid-Derived Suppressor Cells in the Tumor Microenvironment. J Exp Med (2010) 207:2439-53. doi: $10.1084 /$ jem.20100587

23. Colegio OR, Chu NQ, Szabo AL, Chu T, Rhebergen AM, Jairam V, et al. Functional Polarization of Tumour-Associated Macrophages by TumourDerived Lactic Acid. Nature (2014) 513:559-63. doi: 10.1038/nature13490

24. Kitamura T, Qian BZ, Soong D, Cassetta L, Noy R, Sugano G, et al. CCL2Induced Chemokine Cascade Promotes Breast Cancer Metastasis by Enhancing Retention of Metastasis-Associated Macrophages. J Exp Med (2015) 212:1043-59. doi: 10.1084/jem.20141836

25. Hansen W, Hutzler M, Abel S, Alter C, Stockmann C, Kliche S, et al. Neuropilin 1 Deficiency on CD4+Foxp3+ Regulatory T Cells Impairs Mouse Melanoma Growth. J Exp Med (2012) 209:2001-16. doi: 10.1084/ jem.20111497
26. Voron T, Colussi O, Marcheteau E, Pernot S, Nizard M, Pointet AL, et al. VEGF-a Modulates Expression of Inhibitory Checkpoints on CD8+ T Cells in Tumors. J Exp Med (2015) 212:139-48. doi: 10.1084/jem.20140559

27. Gabrilovich DI, Chen HL, Girgis KR, Cunningham HT, Meny GM, Nadaf S, et al. Production of Vascular Endothelial Growth Factor by Human Tumors Inhibits the Functional Maturation of Dendritic Cells. Nat Med (1996) 2:1096-103. doi: 10.1038/nm1096-1096

28. Curiel TJ, Wei S, Dong H, Alvarez X, Cheng P, Mottram P, et al. Blockade of B7-H1 Improves Myeloid Dendritic Cell-Mediated Antitumor Immunity. Nat Med (2003) 9:562-7. doi: 10.1038/nm863

29. Murdoch C, Muthana M, Coffelt SB, Lewis CE. The Role of Myeloid Cells in the Promotion of Tumour Angiogenesis. Nat Rev Cancer (2008) 8:618-31. doi: $10.1038 / \mathrm{nrc} 2444$

30. Noman MZ, Desantis G, Janji B, Hasmim M, Karray S, Dessen P, et al. Pd-L1 is a Novel Direct Target of HIF-1alpha, and its Blockade Under Hypoxia Enhanced MDSC-Mediated T Cell Activation. J Exp Med (2014) 211:781-90. doi: 10.1084/jem.20131916

31. Dang EV, Barbi J, Yang HY, Jinasena D, Yu H, Zheng Y, et al. Control of T(H) 17/T(reg) Balance by Hypoxia-Inducible Factor 1. Cell (2011) 146:772-84. doi: 10.1016/j.cell.2011.07.033

32. Shi LZ, Wang R, Huang G, Vogel P, Neale G, Green DR, et al. HIFlalphaDependent Glycolytic Pathway Orchestrates a Metabolic Checkpoint for the Differentiation of TH17 and Treg Cells. J Exp Med (2011) 208:1367-76. doi: $10.1084 /$ jem. 20110278

33. Clever D, Roychoudhuri R, Constantinides MG, Askenase MH, Sukumar M, Klebanoff CA, et al. Oxygen Sensing by $\mathrm{T}$ Cells Establishes an Immunologically Tolerant Metastatic Niche. Cell (2016) 166:1117-1131 e1114. doi: 10.1016/j.cell.2016.07.032

34. Doedens AL, Phan AT, Stradner MH, Fujimoto JK, Nguyen JV, Yang E, et al. Hypoxia-Inducible Factors Enhance the Effector Responses of CD8(+) T Cells to Persistent Antigen. Nat Immunol (2013) 14:1173-82. doi: $10.1038 /$ ni.2714

35. Baitsch L, Baumgaertner P, Devevre E, Raghav SK, Legat A, Barba L, et al. Exhaustion of Tumor-Specific CD8(+) T Cells in Metastases From Melanoma Patients. J Clin Invest (2011) 121:2350-60. doi: 10.1172/JCI46102

36. Paley MA, Kroy DC, Odorizzi PM, Johnnidis JB, Dolfi DV, Barnett BE, et al. Progenitor and Terminal Subsets of CD8+ T Cells Cooperate to Contain Chronic Viral Infection. Science (2012) 338:1220-5. doi: 10.1126/ science. 1229620

37. Blank CU, Haining WN, Held W, Hogan PG, Kallies A, Lugli E, et al. Defining 'T Cell Exhaustion'. Nat Rev Immunol (2019) 19:665-74. doi: 10.1038/s41577019-0221-9

38. Miller BC, Sen DR, Al Abosy R, Bi K, Virkud YV, LaFleur MW, et al. Subsets of Exhausted CD8(+) T Cells Differentially Mediate Tumor Control and Respond to Checkpoint Blockade. Nat Immunol (2019) 20:326-36. doi: 10.1038/s41590-019-0312-6

39. Nishimura H, Honjo T. Pd-1: An Inhibitory Immunoreceptor Involved in Peripheral Tolerance. Trends Immunol (2001) 22:265-8. doi: 10.1016/s14714906(01)01888-9

40. Tivol EA, Borriello F, Schweitzer AN, Lynch WP, Bluestone JA, Sharpe AH. Loss of CTLA-4 Leads to Massive Lymphoproliferation and Fatal Multiorgan Tissue Destruction, Revealing a Critical Negative Regulatory Role of CTLA-4. Immunity (1995) 3:541-7. doi: 10.1016/1074-7613(95)90125-6

41. Kallies A, Zehn D, Utzschneider DT. Precursor Exhausted T Cells: Key to Successful Immunotherapy? Nat Rev Immunol (2020) 20:128-36. doi: 10.1038/s41577-019-0223-7

42. McLane LM, Abdel-Hakeem MS, Wherry EJ. Cd8 T Cell Exhaustion During Chronic Viral Infection and Cancer. Annu Rev Immunol (2019) 37:457-95. doi: 10.1146/annurev-immunol-041015-055318

43. Turnis ME, Andrews LP, Vignali DA. Inhibitory Receptors as Targets for Cancer Immunotherapy. Eur J Immunol (2015) 45:1892-905. doi: 10.1002/ eji.201344413

44. Doering TA, Crawford A, Angelosanto JM, Paley MA, Ziegler CG, Wherry EJ. Network Analysis Reveals Centrally Connected Genes and Pathways Involved in CD8+ T Cell Exhaustion Versus Memory. Immunity (2012) 37:1130-44. doi: 10.1016/j.immuni.2012.08.021

45. Wang C, Singer M, Anderson AC. Molecular Dissection of CD8(+) T-Cell Dysfunction. Trends Immunol (2017) 38:567-76. doi: 10.1016/j.it.2017.05.008 
46. Yi JS, Du M, Zajac AJ. A Vital Role for interleukin-21 in the Control of a Chronic Viral Infection. Science (2009) 324:1572-6. doi: 10.1126/science.1175194

47. Thomas DA, Massague J. TGF-Beta Directly Targets Cytotoxic T Cell Functions During Tumor Evasion of Immune Surveillance. Cancer Cell (2005) 8:369-80. doi: 10.1016/j.ccr.2005.10.012

48. Speiser DE, Ho PC, Verdeil G. Regulatory Circuits of T Cell Function in Cancer. Nat Rev Immunol (2016) 16:599-611. doi: 10.1038/nri.2016.80

49. Yang M, Soga T, Pollard PJ. Oncometabolites: Linking Altered Metabolism With Cancer. J Clin Invest (2013) 123:3652-8. doi: 10.1172/JCI67228

50. Bengsch B, Ohtani T, Khan O, Setty M, Manne S, O’Brien S, et al. EpigenomicGuided Mass Cytometry Profiling Reveals Disease-Specific Features of Exhausted Cd8 T Cells. Immunity (2018) 48:1029-45.e1025. doi: 10.1016/ j.immuni.2018.04.026

51. Im SJ, Hashimoto M, Gerner MY, Lee J, Kissick HT, Burger MC, et al. Defining CD8+ T Cells That Provide the Proliferative Burst After PD-1 Therapy. Nature (2016) 537:417-21. doi: 10.1038/nature19330

52. Yigit B, Wang N, Ten Hacken E, Chen SS, Bhan AK, Suarez-Fueyo A, et al. SLAMF6 as a Regulator of Exhausted Cd8(+) T Cells in Cancer. Cancer Immunol Res (2019) 7:1485-96. doi: 10.1158/2326-6066.CIR-18-0664

53. Beltra JC, Manne S, Abdel-Hakeem MS, Kurachi M, Giles JR, Chen Z, et al. Developmental Relationships of Four Exhausted Cd8(+) T Cell Subsets Reveals Underlying Transcriptional and Epigenetic Landscape Control Mechanisms. Immunity (2020) 52:825-41.e828. doi: 10.1016/j.immuni. 2020.04.014

54. Chen Z, Ji Z, Ngiow SF, Manne S, Cai Z, Huang AC, et al. Tcf-1-Centered Transcriptional Network Drives an Effector Versus Exhausted Cd8 T Cell-Fate Decision. Immunity (2019) 51:840-55. doi: 10.1016/j.immuni.2019.09.013

55. Seo H, Chen J, Gonzalez-Avalos E, Samaniego-Castruita D, Das A, Wang YH, et al. TOX and TOX2 Transcription Factors Cooperate With NR4A Transcription Factors to Impose CD8(+) T Cell Exhaustion. Proc Natl Acad Sci USA (2019) 116:12410-5. doi: 10.1073/pnas.1905675116

56. Wu T, Ji Y, Moseman EA, Xu HC, Manglani M, Kirby M, et al. The TCF1-Bcl6 Axis Counteracts Type I Interferon to Repress Exhaustion and Maintain T Cell Stemness. Sci Immunol (2016) 1:eaai8593. doi: 10.1126/sciimmunol.aai8593

57. Sharma P, Allison JP. The Future of Immune Checkpoint Therapy. Science (2015) 348:56-61. doi: 10.1126/science.aaa8172

58. Noman MZ, Hasmim M, Messai Y, Terry S, Kieda C, Janji B, et al. Hypoxia: A Key Player in Antitumor Immune Response. A Review in the Theme: Cellular Responses to Hypoxia. Am J Physiol Cell Physiol (2015) 309:C569-79. doi: 10.1152/ajpcell.00207.2015

59. Ohta A, Diwanji R, Kini R, Subramanian M, Ohta A, Sitkovsky M. In Vivo T Cell Activation in Lymphoid Tissues is Inhibited in the Oxygen-Poor Microenvironment. Front Immunol (2011) 2:27. doi: 10.3389/fimmu.2011.00027

60. Caldwell CC, Kojima H, Lukashev D, Armstrong J, Farber M, Apasov SG, et al. Differential Effects of Physiologically Relevant Hypoxic Conditions on T Lymphocyte Development and Effector Functions. J Immunol (2001) 167:6140-9. doi: 10.4049/jimmunol.167.11.6140

61. McNamee EN, Korns Johnson D, Homann D, Clambey ET. Hypoxia and Hypoxia-Inducible Factors as Regulators of T Cell Development, Differentiation, and Function. Immunol Res (2013) 55:58-70. doi: 10.1007/ s12026-012-8349-8

62. Palazon A, Goldrath AW, Nizet V, Johnson RS. HIF Transcription Factors, Inflammation, and Immunity. Immunity (2014) 41:518-28. doi: 10.1016/ j.immuni.2014.09.008

63. Palazon A, Tyrakis PA, Macias D, Velica P, Rundqvist H, Fitzpatrick S, et al. An HIF-1alpha/VEGF-A Axis in Cytotoxic T Cells Regulates Tumor Progression. Cancer Cell (2017) 32:669-83.e665. doi: 10.1016/j.ccell.2017.10.003

64. Liu YN, Yang JF, Huang DJ, Ni HH, Zhang CX, Zhang L, et al. Hypoxia Induces Mitochondrial Defect That Promotes T Cell Exhaustion in Tumor Microenvironment Through Myc-Regulated Pathways. Front Immunol (2020) 11:1906. doi: 10.3389/fimmu.2020.01906
65. O'Connor JP, Rose CJ, Waterton JC, Carano RA, Parker GJ, Jackson A. Imaging Intratumor Heterogeneity: Role in Therapy Response, Resistance, and Clinical Outcome. Clin Cancer Res (2015) 21:249-57. doi: 10.1158/10780432.CCR-14-0990

66. Jansen CS, Prokhnevska N, Master VA, Sanda MG, Carlisle JW, Bilen MA, et al. An Intra-Tumoral Niche Maintains and Differentiates Stem-Like CD8 T Cells. Nature (2019) 576:465-70. doi: 10.1038/s41586-019-1836-5

67. Khouzam RA, Brodaczewska K, Filipiak A, Zeinelabdin NA, Buart S, Szczylik C, et al. Tumor Hypoxia Regulates Immune Escape/Invasion: Influence on Angiogenesis and Potential Impact of Hypoxic Biomarkers on Cancer Therapies. Front Immunol (2021) 11:1-6. doi: 10.3389/fimmu.2020.613114

68. Ferrara N, Hillan KJ, Gerber HP, Novotny W. Discovery and Development of Bevacizumab, an anti-VEGF Antibody for Treating Cancer. Nat Rev Drug Discovery (2004) 3:391-400. doi: 10.1038/nrd1381

69. Kim CG, Jang M, Kim Y, Leem G, Kim KH, Lee H, et al. VEGF-a Drives TOXDependent T Cell Exhaustion in anti-PD-1-resistant Microsatellite Stable Colorectal Cancers. Sci Immunol (2019) 4:eaay0555. doi: 10.1126/ sciimmunol.aay0555

70. Rahma OE, Hodi FS. The Intersection Between Tumor Angiogenesis and Immune Suppression. Clin Cancer Res (2019) 25:5449-57. doi: 10.1158/10780432.CCR-18-1543

71. Fukumura D, Kloepper J, Amoozgar Z, Duda DG, Jain RK. Enhancing Cancer Immunotherapy Using Antiangiogenics: Opportunities and Challenges. Nat Rev Clin Oncol (2018) 15:325-40. doi: 10.1038/nrclinonc.2018.29

72. Croci DO, Mendez-Huergo SP, Cerliani JP, Rabinovich GA. ImmuneMediated and Hypoxia-Regulated Programs: Accomplices in Resistance to Anti-angiogenic Therapies. Handb Exp Pharmacol (2018) 249:31-61. doi: 10.1007/164_2017_29

73. Motz GT, Coukos G. The Parallel Lives of Angiogenesis and Immunosuppression: Cancer and Other Tales. Nat Rev Immunol (2011) 11:702-11. doi: 10.1038/nri3064

74. LaFleur MW, Nguyen TH, Coxe MA, Miller BC, Yates KB, Gillis JE, et al. PTPN2 Regulates the Generation of Exhausted CD8(+) T Cell Subpopulations and Restrains Tumor Immunity. Nat Immunol (2019) 20:1335-47. doi: 10.1038/s41590-019-0480-4

75. Hill M, Segovia M, Russo S, Girotti MR, Rabinovich GA. The Paradoxical Roles of Inflammation During PD-1 Blockade in Cancer. Trends Immunol (2020) 41:982-93. doi: 10.1016/j.it.2020.09.003

76. Chevrier S, Levine JH, Zanotelli VRT, Silina K, Schulz D, Bacac M, et al. An Immune Atlas of Clear Cell Renal Cell Carcinoma. Cell (2017) 169:73649.e718. doi: 10.1016/j.cell.2017.04.016

77. Giraldo NA, Becht E, Pages F, Skliris G, Verkarre V, Vano Y, et al. Orchestration and Prognostic Significance of Immune Checkpoints in the Microenvironment of Primary and Metastatic Renal Cell Cancer. Clin Cancer Res (2015) 21:3031-40. doi: 10.1158/1078-0432.CCR-14-2926

78. Siska PJ, Beckermann KE, Mason FM, Andrejeva G, Greenplate AR, Sendor $\mathrm{AB}$, et al. Mitochondrial Dysregulation and Glycolytic Insufficiency Functionally Impair CD8 T Cells Infiltrating Human Renal Cell Carcinoma. JCI Insight (2017) 2:e93411. doi: 10.1172/jci.insight.93411

Conflict of Interest: The authors declare that the research was conducted in the absence of any commercial or financial relationships that could be construed as a potential conflict of interest.

Copyright (๑) 2021 Bannoud, Dalotto-Moreno, Kindgard, García, Blidner, Mariño, Rabinovich and Croci. This is an open-access article distributed under the terms of the Creative Commons Attribution License (CC BY). The use, distribution or reproduction in other forums is permitted, provided the original author(s) and the copyright owner(s) are credited and that the original publication in this journal is cited, in accordance with accepted academic practice. No use, distribution or reproduction is permitted which does not comply with these terms. 